\title{
Impact of blowing agents in poly(vinyl chloride) cellular extrusion process
}

\author{
Tomasz Garbacz ${ }^{1 *}$, L'udmila Dulebová ${ }^{2}$ \\ ${ }^{1}$ Lublin University of Technology, Mechanical Engineering Faculty, Department of Technology and Polymer Processing, 36 Nadbystrzycka St., 20-618 \\ Lublin, Poland \\ ${ }^{2}$ Technical University of Košice, Department of Automobile Production, Faculty of Mechanical Engineering 74 Mäsiarska St., 04001 Košice, Slovakia
}

\begin{abstract}
In dependence on the type and later application, the layers of cables are made from many different kinds of polymers. However, most often, because of good mechanical properties and many other advantages, they are first of all made from polyvinyl chlorine (PVC). The aim of the conducted research was to discover the influence of modifying PVC with selected agents that is a blowing agent, in the course of the extrusion process, inclusive of determination how the modification affects selected technological properties and properties of the surface of PVC extrusion product. The article presents specification of cellular extrusion process of thermoplastics. In the research, endothermic and exothermic chemical blowing agents in the amount of $1.5 \%$ by mass were used. The experiments involved measuring output, energy consumption and energy efficiency of the process.
\end{abstract}

Keywords: Extrusion, effectiveness, poly(vinyl chloride), chemical blowing agents.

\section{Introduction}

Extrusion of cellular plastics differs from extrusion of solid plastics in that the product obtained as a result of the processing procedure is formed into a diphase plastic-gas structure, with possibly smallest and evenly distributed gas bubbles. Cellular structure is obtained due to the insertion of the blowing agent (porophor) in the form of inert gas, low-boiling liquid or a solid body into the moulding compound which, when in liquid or solid state, transforms into gas under the determined conditions of the extrusion process [1,2].

When, in the proper temperature, the process of gas emission is started, numerous microspheres which are then generated dissolve in the surrounding plastic material due to the operation of pressure and surface development. The emerging cells may be filled in with air or with any other gases, for instance $\mathrm{CO}_{2}$ and $\mathrm{N}_{2^{\prime}}$ yet later they are replaced with air as a result of diffusion $[1,2,3]$. Stream of the processed plastic material, together with the gas dissolved therein, is transported under pressure to the pre-forming head. The pressure should be high enough to prevent emission of gas as a separate phase (micro-bubbles) until the mouth of extruder die. If this happened, membranes separating gas bubbles would suffer mechanical damage as a result of tangential stress occurring in the processed plastic material, and thus obtaining homogeneous cellular structure would not be possible. Plastic pressure increases along the plasticizing unit, slightly decreases in the terminal section of the system and at the front of the extruder head, and rapidly decreases inside the 
die reaching the value of atmospheric pressure.

The effects of polymers extrusion using the blowing agents are new and modified physical and technological properties of cellular products $[3,4,5]$. These are for example: smaller density of received product, better damping properties, small processing shrinkage, better damping and insulating properties, bigger resistance to fire and the possibility of utilization after using.The examination of the process of extrusion, which was conducted by the Lublin Technical University attended by the authors of this article, among others, refers to the production of the covering of cables of different types and various applications of cellular plastics (example on Fig. 1) [3, 4, 5]
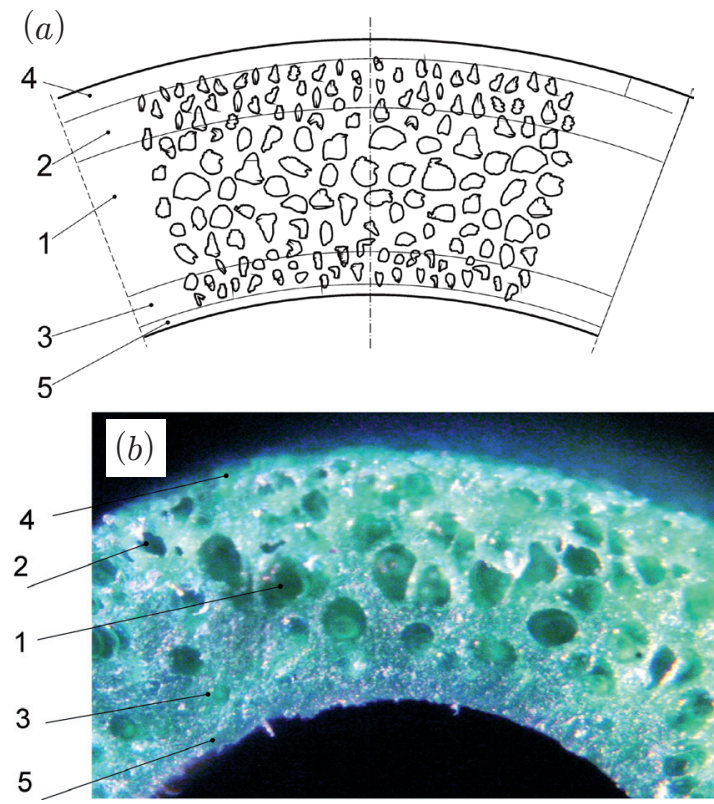

Fig. 1: Cross - section view of PVC cellular multilayer: 1 - core zone, 2,3 - indirect zones, 4, 5- surface zones. [4]

This process leads to the replacement of the conventional extrusion of the covering with the cellular extrusion process. The research of the cellular extrusion of thermoplastic polymers refers to the process of modifying product properties in the way of porous of the basic polymer with use of a blowing agent and also through a change of the extrusion conditions and construction features of the elements of the plastifying system and the extrusion head $[3,4,6]$. Autors $[6,7,8]$ investigated the extrusion process with regard to decomposition, number of cells, mechanical properties and structure of cellular extruded products made of HDPE/PP, PVC. The studies conducted by P. Palutkiewicz [5] to investigate the effectiveness of manufacturing cellular products are also significant. Nonetheless, it must be emphasized that the above studies focused on cellular injection molding and the effect of modified processing conditions in a singlescrew plasticizing unit on physical properties of manufactured products. The studies [3, 8. 9] also describe the effectiveness of producing cellular products, yet only with regard to the material effectiveness at variable extrusion conditions. This method causes a product of different properties to be received and takes effect in the decrease of the cost of purchase of polymers, increase of the extrusion efficiency, lower cost of energy of the process as well as lower transport costs in the course of manufacturing cellular products.

The aim of the conducted research was to discover the influence of modifying PVC with selected agents that is a blowing agent, in the course of the extrusion process, inclusive of determination how the modification affects selected physical properties and properties of the surface of PVC extrusion product. Another objective was assessment of the examined polymer in terms of required conditions and properties of porous product. The article presents specification of cellular extrusion process of thermoplastics.

\section{Experimental}

One problem that is rarely discussed and still inadequately investigated concerns the effect of various blowing agents (exothermic, endothermic, pellets or microspheres) on the effectiveness of cellular extrusion. The results reported in the studies demonstrate that the chemical properties of the blowing agents facilitate the polymer flow in the plasticizing unit and extruder head. They do not determine, however, if the blowing agents have any impact on the effectiveness and efficiency of the extrusion process.

The materials used in the experiments included plasticized poly(vinyl chloride) (PVC) and three types of chemical blowing agents. Polyvinyl chloride (PVC) manufactured by Alfa PVC Sp. z o.o (Poland)., having a trade name Alfavinyl GMF/431TR, was used in the study on cellular extrusion 
process. This plastic has density ranges from 1230 to $1400 \mathrm{~kg} / \mathrm{m}^{3}$ and hardness of $80 \mathrm{Sh}^{\circ} \mathrm{A}$ (according to data provided by the producer). Its density $\rho_{\left(23 \pm 2^{\circ} \mathrm{C}\right)} \mathrm{kg} / \mathrm{m}^{3}$, the mass flow rate $\operatorname{MFR}_{\left(150^{\circ} / 110,29 \mathrm{~kg}\right)}$ is between 4.3 and $4.6 \mathrm{~g} / 10 \mathrm{~min}$, the tensile strength at break is $\geq 21 \mathrm{MPa}$.

In accordance with the established research program, plastic intended for extrusion was modified by introducing the blowing agent during the stirring process. In the research presented in the article, a blowing system having a trade name of Hydrocerol 531, produced by Clariant Masterbatch Division LyCell-F017 manufactured by Ly-TeC GmbH, and Expancel 950 MB80 manufactured by Akzo Nobel was used. Chemical blowing agents are modifying agents that react at elevated temperatures and cause the cleavage of organic or inorganic bonds, thus producing gas and, eventually, creating a cellular structure. The blowing agents applied in the experiments had the form of pellets and, as a result, they could be mechanically mixed with the polymer being processed. The decomposition products of the applied blowing agents mainly include carbon dioxide $\mathrm{CO}_{2}$, a small amount of water $\mathrm{H}_{2} \mathrm{O}$ and nitrogen $\mathrm{N}_{2}$. Selected properties of the discussed blowing agents are listed in Table 1.

Table 1: Selected properties of blowing agents used in the cellular extrusion process.

\begin{tabular}{|l|l|l|l|l|}
\hline No. & $\begin{array}{l}\text { Characteristic } \\
\text { quantity }\end{array}$ & LyCell-F017 & $\begin{array}{l}\text { Hydrocerol } \\
530\end{array}$ & $\begin{array}{l}\text { Expancel } \\
\mathbf{9 5 0} \mathbf{M B} 80\end{array}$ \\
\hline 1 & Distribution & Endothermic & Exothermic & $\begin{array}{l}\text { Endothermic } \\
\text { microspheres }\end{array}$ \\
\hline 2 & $\left.\begin{array}{l}\text { Decomposition } \\
\text { initiation, }\end{array}{ }^{\circ} \mathrm{C}\right)$ & 140 & 140 & 130 \\
\hline 3 & $\left.\begin{array}{l}\text { Optimum processing } \\
\text { temperature, }\end{array}{ }^{\circ} \mathrm{C}\right)$ & $150-190$ & $150-170$ & $130-190$ \\
\hline 4 & $\begin{array}{l}\text { Extrusion dosage, (\%) } \\
0.5-2.5\end{array}$ & $0.5-2.0$ & $0.5-2.5$ \\
\hline
\end{tabular}

Hydrocerol 530 is an exothermic blowing agent with nucleating properties. The active substances in this blowing agent constitute a mixture of appropriately proportioned chemical compounds such as azodicarbonamide. LyCell-F017 is an endothermic blowing agent. This blowing agent is a mixture of sodium acid carbonate and 2hydroxypropane-tricarboxylic acid (citric acid). Expancel 950 MB 80 is a blowing agent that has the form of spherical thermoplastic polymer capsules (microspheres) that contain a hydrocarbon gas. This is an endothermic blowing agent. Expancel microspheres do not bond because the capsules retain their blocking properties, which prevents release of the constrained gas. In the research, endothermic chemical blowing agents in the amount of $1.5 \%$ by mass were used.

The experimental tests were conducted on a laboratory technological line for profile extrusion, its main component being a double-screw extruder EHP 2x20 Sline (Fig. 2, Fig. 3), produced by Zamak Mercator (Poland). The extruder's plasticizing unit had four heating zones, the screw had an L/D ratio of 25 and an outside diameter, D, of $20 \mathrm{~mm}$. The rotational speed of the extruder screw ranged from 0 to 200 revolutions per minute and was adjusted continuously. The technological line also consisted of a head for profile extrusion. The head had a replaceable extruder die to enable extrusion of profiles with different sizes and shapes, both symmetric and asymmetric.



Fig. 2: View of technological line for cellular extrusion; head with a die for tape producing, and with the tape produced.

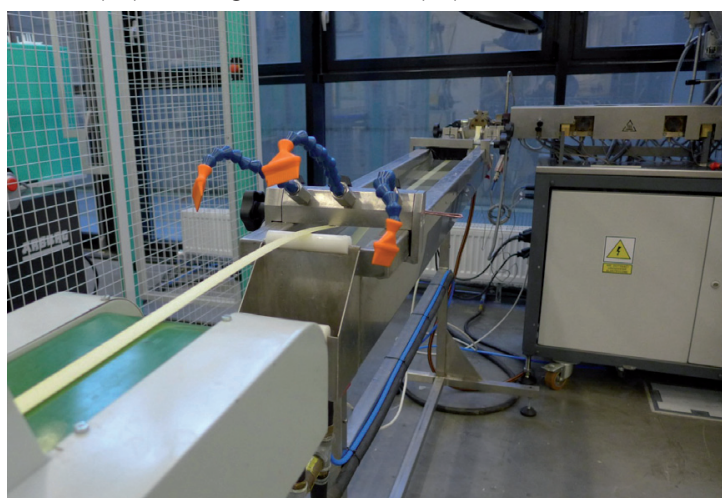

Fig. 3: View of technological line for cellular extrusion; single screw extruder, cooling device, receiving device, extrudate. 
Used for tape profile extrusion, the die had a width of $15.5 \mathrm{~mm}$ and a height of $2.0 \mathrm{~mm}$. The extruder head was made up of two heating zones and two corresponding ring-shaped heaters mounted on the head body. The extrusion line also consisted of a cooling device that had a length of $1740 \mathrm{~mm}$, width of $220 \mathrm{~mm}$ and depth of $200 \mathrm{~mm}$ In the tests, we also used a belt haul-off; the belt had a width of $100 \mathrm{~mm}$ and a length of $2000 \mathrm{~mm}$.

The extrusion process was carried out under the developed and imposed conditions, set in the extrusion process line. They included the following: temperature values of heating zones in the plasticizing unit were respectively: 150, 170, 170 and $185^{\circ} \mathrm{C}$; temperature values in the head for the three heating zones were respectively: 160, 160 and $150^{\circ} \mathrm{C}$. The determined rate of screw rotation was altered within the range of 50-100 rot./min)., whereas the receiving speed of the manufactured cable coating was $150 \mathrm{~m} / \mathrm{min}$. Temperature of the cooling agent was $12 \div 14^{\circ} \mathrm{C}$.

This set included directly and indirectly investigated parameters, as well as variable, constant and disturbing parameters. The following parameters were investigated in the experimental tests:

- weight of the measuring length of the extrudate, $m_{e}, k g$,

- number of revolutions of the electric energy meter, $n$, rev.

- mass flow rate of the polymer ( mass efficiency of the extrusion process) $G(g / s)$

\section{volumetric flow rate of the polymer $V\left(\mathrm{~cm}^{3} / \mathrm{s}\right)$}

$\checkmark$ power supplied to the extruder Qe (kW)

$\checkmark$ power conveyed by the polymer $\left.\mathrm{Qp}_{\mathrm{p}} \mathrm{kW}\right)$

$\checkmark$ energy efficiency of the extrusion process $\eta_{e}(\%)$

The variable parameters were:

content of the blowing agent in the polymer: $0.5,1.0,1.5 \% \mathrm{w} / \mathrm{w}$

- number of revolutions of the extruder screw $v: 50,65,80,100$ revolutions per minute.

During the tests, the following were measured: the electric energy consumption, the temperature of the extrudate on leaving the extruder head die and the weight of the tape produced in the processing. After the measurements, the rotational speed of the screw was increased and once the process became stable, we measured the energy, temperature and weight of the produced tape applying another rotational speed of the screw

\section{Results}

The blowing agent was dosed in $0.5-1.5 \%$ by weight, so as to produce extrudate (tape) with a solid surface and a cellular core. The shape and outside dimensions of the product agree with shape and dimensions of solid products made of the tested PVC. The photographs of the cross section of the tape were taken on the stand for image analysis of cellular plastics that consisted of the Nikon SMZ1500 metallographic microscope equipped with a digital camera, the DS - U3 sensor and a personal computer with suitable NIS Elements Advanced Research software (Fig. 4).

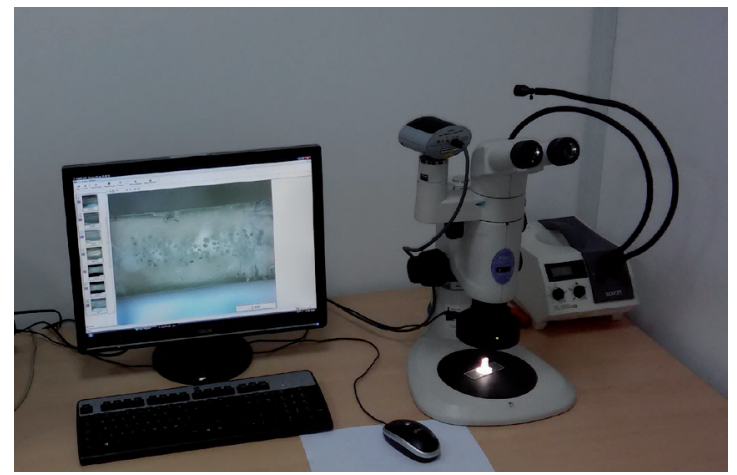

Fig. 4: View for image analysis of porous structure, Nikon SMZ1500 stand.

The macroscopic structure of the produced cellular tapes was examined at the stand for polymer cellular structure image analysis. The stand comprised a metallographic, optical image recording devices and a computer equipped with specialist software. The examples of the cellular structure of coatings produced are shown in Figures from 5 to 8

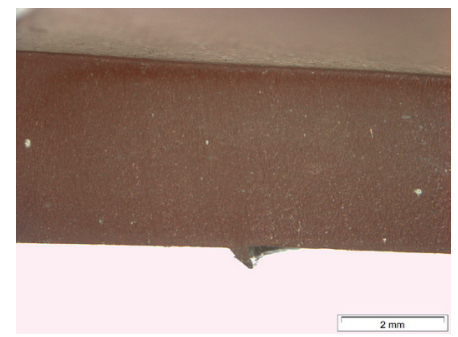

Fig. 5: Fragment of the cross section of the solid tapes with PVC.

The coatings made of PVC with $0.5 \%$ blowing agent (Expancel 950 MB80 and LyCell-F017) content do not have sufficiently cellular structure (Fig. 6, 7)

The cell dispersion patterns in the structure 
could be attributed to the non-uniform dosing of a very small blowing agent amount into the polymer and the characteristics of the applied blowing agent with the endothermic decomposition behavior. The tapes produced with the blowing agent content amounting to $1.5 \%$ or more had a uniform cellular structure, especially in terms of the thickness of the coating produced (Fig. 8).

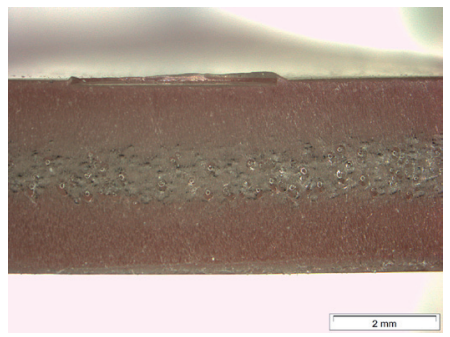

Fig. 6: Fragment of the cross section of the tapes produced with 0.5 wt. \% of the blowing agent (Expancel 950 MB80).

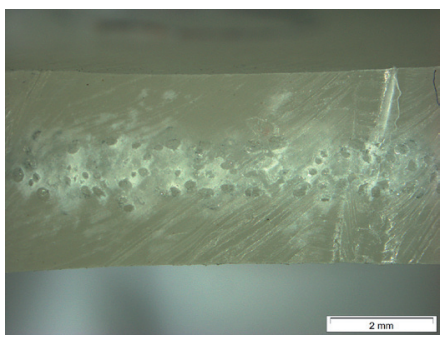

Fig. 7: Fragment of the cross section of the tapes produced with 0.5 wt. \% of the blowing agent (LyCell-F017).

Based on the analysis of the photographs taken, it can be seen that the coating with the 0.5\% blowing agent contents has a visible solid outer layer and most uniform distribution of similarly sized cells (Fig. 7). In contrast, the coating with the 1.0 and $1.5 \%$ blowing agent content has a visible concentration of similarly sized cells (Fig. 8) that can - in extreme cases - lead to the discontinuity of the product covering solid outer layer.

Based on the experimental results of poly(vinyl chloride) cellular extrusion, we could determine the relationships between the mass and volumetric flow rates of the polymer, the power supplied to the extruder and conveyed by the polymer as well as the energy efficiency of extrusion and the type and content of the blowing agents and rotational speed of the extruder screw. The results of the direct parameters are listed in Tables 2-4. give the results of the resulting parameters that describe

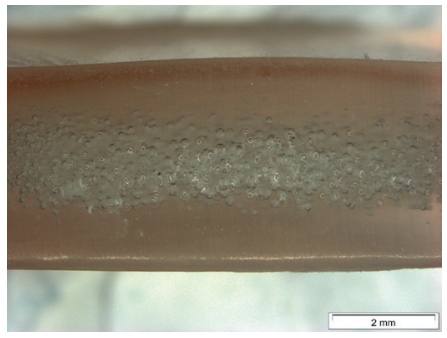

Fig. 8: Fragment of the cross section of the tapes produced with 1.5 wt. \% of the blowing agent (Hydrocerol 531).

the effectiveness of cellular extrusion. A selection of the experimental results is given in Figures 9 through 14.

We did not observe any relationship between the type of the blowing agent applied (endothermic or exothermic) and the energy consumption determined on the basis of the number of revolutions shown by the electricity meter. Nevertheless, a twofold increase in the rotational speed of the screw increased the energy consumption of the process by approx. 12\%, irrespective of the blowing agent applied.

Examining the results of the extrudate weight and the polymer mass flow rate (Tab. 2, Fig. 9), it can be claimed that the effectiveness of cellular extrusion increases with increasing the rotational speed of the screw. This increase is, however, dependent on the blowing agent applied and its content. On the average, the endothermic blowing agent increased the process output by $15 \%-27 \%$ for $0.5 \%, 1 \%$ and $1.5 \%$ of this blowing agent, respectively. The addition of the exothermic blowing agent increased the process efficiency, on the average, by $25 \%, 23 \%, 20 \%$.

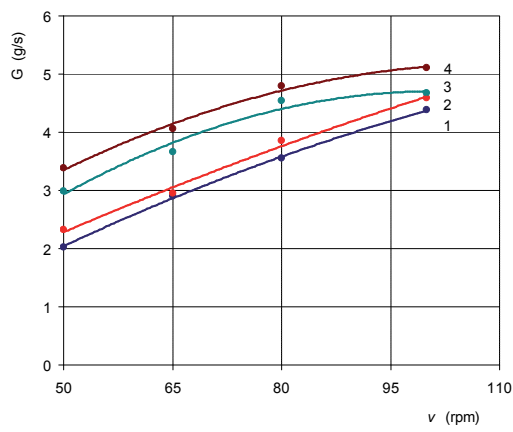

Fig. 9: Dependence of mass flow rate G of cellular PVC with the use of endothermic blowing agent (Expancel $950 M B 80$ ) in the function of screw rotational speed $v$ : 1, PVC solid; 2, PVC $+0.5 \%$ Expancel; 3 , PVC $+1.0 \%$ Expancel; 4, PVC $+1.5 \%$ Expancel. 
Table 2: Cellular extruded moving out head die temperature results and electrics energy consuming (veryfied by number of rotations of electricity meter) depending on the blowing agent used and extruder screw rotational speed.

\begin{tabular}{|c|c|c|c|c|c|c|c|c|c|}
\hline \multirow{3}{*}{ Type of material } & \multirow{3}{*}{$\begin{array}{c}\text { Content of } \\
\text { blowing agent } \\
\text { (\%) }\end{array}$} & \multicolumn{8}{|c|}{ Screw rotational speed $v(\mathrm{rpm})$} \\
\hline & & 50 & 65 & 80 & 100 & 50 & 65 & 80 & 100 \\
\hline & & \multicolumn{4}{|c|}{ Average temperature of extrudate ${ }^{\circ}\left({ }^{\circ} \mathrm{C}\right)$} & \multicolumn{4}{|c|}{ Number of rotations of electricity meter } \\
\hline PVC solid & 0 & 140 & 144 & 144 & 147 & 9.5 & 11.0 & 10.5 & 11.0 \\
\hline \multirow{3}{*}{ PVC+ Expancel 950MB 80} & 0.5 & 144 & 146 & 146 & 150 & 10.0 & 10.2 & 11.0 & 11.0 \\
\hline & 1.0 & 144 & 146 & 146 & 150 & 10.5 & 9.0 & 10.4 & 11.8 \\
\hline & 1.5 & 150 & 152 & 152 & 152 & 9.0 & 8.0 & 9.1 & 11.0 \\
\hline \multirow{3}{*}{ PVC + LyCell-F017 } & 0.5 & 145 & 149 & 151 & 153 & 10.0 & 9.8 & 9.9 & 11.5 \\
\hline & 1.0 & 151 & 155 & 155 & 156 & 10.6 & 10.0 & 10.5 & 11.5 \\
\hline & 1.5 & 150 & 152 & 154 & 156 & 11.0 & 10.5 & 10.2 & 11.0 \\
\hline \multirow{3}{*}{ PVC + Hydrocerol 530} & 0.5 & 165 & 165 & 165 & 166 & 10.2 & 10.8 & 9.5 & 11.5 \\
\hline & 1.0 & 167 & 167 & 167 & 168 & 10.0 & 10.5 & 10.0 & 10.8 \\
\hline & 1.5 & 167 & 167 & 168 & 168 & 10.6 & 10.6 & 9.8 & 11.0 \\
\hline
\end{tabular}

Table 3: Mass me results and mass flow rate G calculations of cellular extrudate depending on the blowing agent used and extruder screw rotational speed $v$.

\begin{tabular}{|c|c|c|c|c|c|c|c|c|c|}
\hline \multirow{4}{*}{ Type of material } & \multirow{4}{*}{$\begin{array}{l}\text { Content of } \\
\text { blowing agent } \\
\text { (\%) }\end{array}$} & \multicolumn{8}{|c|}{ Screw rotational speed $v(\mathrm{rpm})$} \\
\hline & & 50 & 65 & 80 & 100 & 50 & 65 & 80 & 100 \\
\hline & & \multicolumn{4}{|c|}{ Average mass of extrudate me } & \multicolumn{4}{|c|}{ Polymer mass flow rate $G$} \\
\hline & & \multicolumn{4}{|c|}{ (g) } & \multicolumn{4}{|c|}{$(g / s)$} \\
\hline PVC solid & 0 & 60.9 & 87.0 & 106.5 & 131.5 & 2.03 & 2.90 & 3.55 & 4.38 \\
\hline \multirow{3}{*}{$P V C+$ Expancel 950MB 80} & 0.5 & 69.7 & 88.6 & 115.6 & 137.9 & 2.32 & 2.95 & 3.85 & 4.59 \\
\hline & 1.0 & 89.7 & 11.0 & 136.4 & 140.1 & 2.99 & 3.66 & 4.54 & 4.67 \\
\hline & 1.5 & 10.6 & 121.9 & 143.9 & 153.4 & 3.38 & 4.06 & 4.79 & 5.11 \\
\hline \multirow{3}{*}{$P V C+$ LyCell-F017 } & 0.5 & 96.2 & 111.5 & 143.3 & 143.6 & 3.20 & 3.71 & 4.77 & 4.78 \\
\hline & 1.0 & 105.7 & 122.8 & 146.7 & 153.0 & 3.52 & 4.09 & 4.85 & 5.10 \\
\hline & 1.5 & 113.7 & 133.4 & 145.7 & 155.2 & 3.79 & 4.44 & 4.89 & 5.17 \\
\hline \multirow{3}{*}{$P V C+$ Hydrocerol 530} & 0.5 & 73.8 & 92.2 & 110.1 & 142.0 & 2.46 & 3.07 & 3.67 & 4.73 \\
\hline & 1.0 & 75.8 & 101.0 & 110.9 & 142.3 & 2.52 & 3.36 & 3.69 & 4.74 \\
\hline & 1.5 & 82.1 & 101.4 & 111.3 & 143.8 & 2.73 & 3.38 & 3.71 & 4.79 \\
\hline
\end{tabular}

The results of the amount of energy supplied to the extruder and the polymer in processing, calculated based on the results of the power Qe supplied to the extruder and the power $Q_{p}$ conveyed by the polymer, reveal the effect of the variable parameters, i.e. the type and content of the blowing agent and screw rotational speed, on the investigated parameters (Tab. 3, Fig. 10-13).

The increase in the rotational speed of the screw and concentration of the blowing agent led to an increase in the power conveyed by the polymer.
The highest increase in power was observed when the endothermic blowing agent was applied (Fig. 10, 11). With the increase in the rotational speed of the screw, the polymer-conveyed power increased on the average by $28 \%$ at $0.5 \%, 42 \%$ at $1.0 \%$ and $49 \%$ at $1.5 \%$ content of the blowing agent. The addition of Expancel 950 MB 80 (Tab. 3) led to an increase in the polymer-conveyed power, on the average by $10 \%$ at $0.5 \%, 30 \%$ at $1.0 \%$ and $42 \%$ at $1.5 \%$ by weight, respectively. 


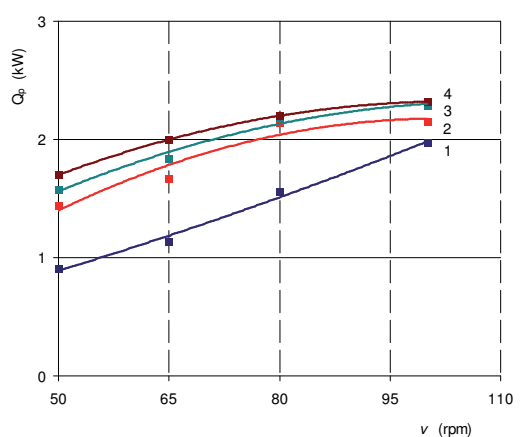

Fig. 10: Power conveyed by the polymer $Q_{p}$ with the use of endothermic blowing agent (LyCell F017) in the function of the screw rotational speed $v$ during the extrusion of studied polymers: 1, PVC solid; 2, PVC + 0.5\% LyCell; 3, PVC + 1.0\% LyCell; 4, PVC +1.5\% LyCell.

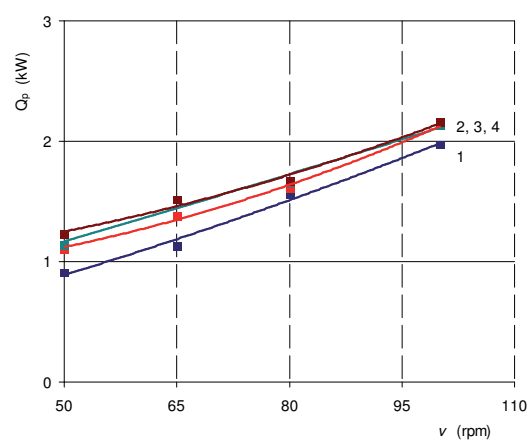

Fig. 11: Power conveyed by the polymer $Q_{p}$ with the use of egzothermic blowing agent (Hydrocerol 530) in the function of the screw rotational speed $v$ during the extrusion of studied polymers: 1, PVC solid; 2, PVC $+0.5 \%$ Hydrocerol; 3, PVC $+1.0 \%$ Hydrocerol; 4 , PVC $+1.5 \%$ Hydrocerol.

Table 4: Results of volumetric flow rate of the polymer $V$ and energy efficiency $\eta_{e}$ of the extrusion process depending on the blowing agent used and extruder screw rotational speed $v$.

\begin{tabular}{|c|c|c|c|c|c|c|c|c|c|}
\hline \multirow{4}{*}{ Type of material } & \multirow{4}{*}{$\begin{array}{l}\text { Content of } \\
\text { blowing agent } \\
\text { (\%) }\end{array}$} & \multicolumn{8}{|c|}{ Screw rotational speed $v(\mathrm{rpm})$} \\
\hline & & 50 & 65 & 80 & 100 & 50 & 65 & 80 & 100 \\
\hline & & \multicolumn{4}{|c|}{ Volumetric flow rate $\mathrm{V}$} & \multicolumn{4}{|c|}{ Energy efficiency $\eta_{e}$} \\
\hline & & \multicolumn{4}{|c|}{$\left(\mathrm{cm}^{3} / \mathrm{s}\right)$} & \multicolumn{4}{|c|}{ (\%) } \\
\hline PVC solid & 0 & 1.60 & 2.29 & 2.81 & 3.48 & 21.40 & 23.73 & 30.43 & 35.54 \\
\hline \multirow{3}{*}{$P V C+$ Expancel 950MB 80} & 0.5 & 1.84 & 2.34 & 3.05 & 3.65 & 23.25 & 36.41 & 37.29 & 37.27 \\
\hline & 1.0 & 2.37 & 2.91 & 3.61 & 3.71 & 29.90 & 41.77 & 39.35 & 42.89 \\
\hline & 1.5 & 2.70 & 3.23 & 3.81 & 4.06 & 40.13 & 36.94 & 42.32 & 38.35 \\
\hline \multirow{3}{*}{ PVC + LyCell-F017 } & 0.5 & 2.54 & 2.95 & 3.80 & 3.81 & 26.41 & 47.79 & 43.42 & 40.64 \\
\hline & 1.0 & 2.80 & 3.26 & 3.87 & 4.06 & 33.03 & 51.17 & 41.21 & 52.16 \\
\hline & 1.5 & 3.01 & 3.53 & 3.89 & 4.13 & 45.48 & 37.75 & 41.91 & 43.51 \\
\hline \multirow{3}{*}{ PVC + Hydrocerol 530} & 0.5 & 1.97 & 2.46 & 2.94 & 3.80 & 20.13 & 39.51 & 34.41 & 34.92 \\
\hline & 1.0 & 2.03 & 2.70 & 2.97 & 3.79 & 20.86 & 34.83 & 36.98 & 33.09 \\
\hline & 1.5 & 2.20 & 2.70 & 2.97 & 3.85 & 30.41 & 28.70 & 28.54 & 35.96 \\
\hline
\end{tabular}

The results of power supplied to the extruder demonstrate that this parameter increases in each tested case whenever the rotational speed of the screw is increased. We did not observe, however, any dependencies between the content and type of the blowing agent and the power supplied to the extruder at various rotational speeds (Tab. 3).

The results of the volumetric flow rate of the polymer given in Tab. 4 and in Fig. 12 reveal the relationships similar to those between the polymer mass flow rate and the type of the blowing agent versus different rotational speeds of the screw. The measurement of the amount of energy supplied to the extruder and polymer in processing allowed us to determine the energy efficiency of cellular extrusion. The results of energy efficiency $\eta_{\text {e }}$ of the extrusion process given in Tab. 4 and in Fig. 13, 14. The energy efficiency in PVC extrusion with no blowing agent applied was approx. $28 \%$ (Tab.4).

The experimental results demonstrate that the increase in energy efficiency is caused by both a higher rotational speed of the screw and the type of the blowing agent applied. However, there is no relationship between the percentage of the blowing agent applied and energy efficiency of the cellular extrusion process. 


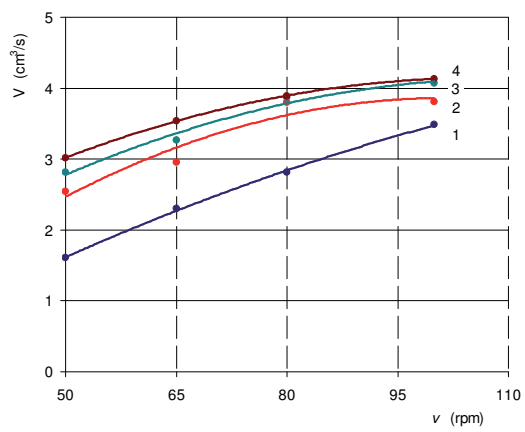

Fig. 12: Dependence of volumetric flow rate of the polymer $V$, with the use of endothermic blowing agent (LyCell F017) in the function of the screw rotational speed $v$ during the extrusion of studied polymers: 1, PVC solid; 2, PVC + 0.5\% LyCell; 3, PVC + 1.0\% LyCell; 4, PVC $+1.5 \%$ LyCell.



Fig. 13: Dependence of energy efficiency $\eta_{e}$ of the extrusion process with the use of endothermic blowing agent (Expancel 950MB 80 ) in the function of screw rotational speed $v: 1$, PVC solid; 2, PVC $+0.5 \%$ Expancel; 3, PVC $+1.0 \%$ Expancel; 4, PVC $+1,5 \%$ Expancel.

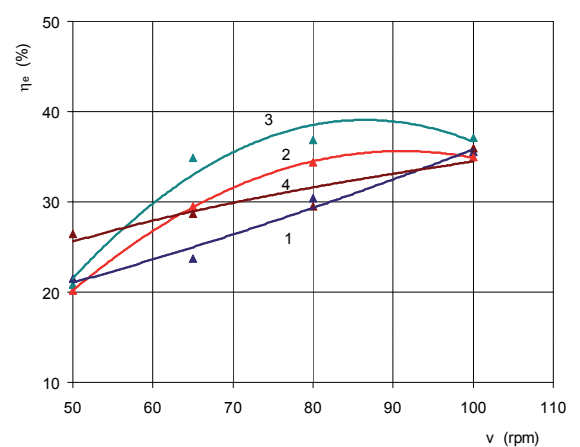

Fig. 14: Dependence of energy efficiency $\eta_{e}$ of the extrusion process with the use of endothermic blowing agent (Hydrocerol 530) in the function of screw rotational speed $v$ during the extrusion of studied polymers: 1, PVC solid; 2, PVC $+0.5 \%$ Hydrocerol; 3, PVC + 1.0\% Hydrocerol; 4 , PVC $+1.5 \%$ Hydrocerol.

\section{Conclusions}

The experimental results of cellular extrusion demonstrate that the decomposition characteristics of the blowing agent (endothermic or exothermic) and its content in the polymer being processed affect the extrusion process and its effectiveness.

Chemical properties of the applied blowing agents facilitate the flow of the polymer through the plasticizing unit and extruder head, which has a direct impact on the output and efficiency of extrusion. This agrees with the observations reported in the studies $[1,2,5]$ devoted to the use of blowing agents with different decomposition characteristics in polymer processing and their impact on the polymer being processed. As for products foamed using endothermic blowing agents, the gas production that occurs in the course of processing ends with cutting off the power supply (endothermic blowing agent). The produced cellular structure is uniform, with the cells having a spherical or spherical-like shape. The cells are of similar size, irrespective of their position in the product.

The application of the blowing agent with an exothermic decomposition behaviour results in producing a tapes with a more cellular structure. This is due to the characteristics of this blowing agent. The initiated exothermic decomposition of the blowing agent runs in an uncontrolled manner, even after the power supply has been cut off. For this reason, products foamed with such blowing agents have a non-uniform cellular structure.

The exothermic blowing agent produces heat during processing, which leads to the lowest increase in the extrusion output and energy efficiency. We did not observe, however, any noticeable effect of this blowing agent on the magnitude of the power supplied to the extruder. It must be noted, however, that the above observations are reliable only with regard to the blowing agent contents applied in the discussed experiments.

\section{Acknowledgments}

This work was supported by the project VEGA 1/0424/17 granted by Scientific grant agency VEGA of Ministry of Education, Science, Research and Sport Slovak Republic. 


\section{References}

[1] Zhou Q., Chuan-Bo C. (2005). Exo-endothermic blowing agent and its blowing behavior. Journal of Cellular Plastics 41, 225-234

[2] Okamoto K. T. (2003). Microcellular processing. Hanser Publishers, Munich, Germany.

[3] Garbacz T., Dulebova L. (2013). Porophors during the extrusion process. Chemistry and Chemical Technology 7, 1, 113118.

[4] Garbacz T. (2011). Properties of triple-layered PVC coatings synthesized in the micropore coextrusion method. Polimery 56, 7-8, 129-134.

[5] Tor-Świątek A. (2013). Evaluation of the effectiveness of the microcellular extrusion process of low density polyethylene. Maintenance and Reliability 15, 3, 225-229.

[6] Martial S., Jacques F., Audrey C., Clémence N., Rodier E. (2011). New challenges in polymer foaming: A review of extrusion processes assisted by supercritical carbon dioxide, „Progress in Polymer Science", 36, 749-766.

[7] Urbanczyk L., Alexandre M., Detrembleur Ch. (2010). Extrusion foaming of poly(styrene-coacrylonitrile)/Clay nanocomposites using supercritical $\mathrm{CO}_{2}$, Macromolecural Material Engenering, 295, 915-922.

[8] Guo M.C., Heuzey M.C., Carreau P.J. (2007). Cell structure and dynamic properties of injection molded polypropylene foams. Polymer Engineering and Science 47, 1070-1081.

[9] Palutkiewicz P., Postawa P. (2016). The investigation of selected properties of the porous moulded parts from talcfilled PP composites. Journal of Cellular Plastics 52, 4, 399418.

\section{Biographical notes}

Assoc. prof. Tomasz Garbacz, Ing. PhD. He is a graduate of Mechanical Engineering Faculty of Lublin University of Technology in 1992 and PhD. degree in 2002. He is associated profesor of the Department of Technology and Polymer Processing at the Lublin University of Technology from 2016. Hes scientific and research work focuses on theoretical and experimental research of selected aspects of polymer processing, research of the efficiency of the modified thermoplastics extrusion process and the polymer cellular extrusion process, as well as the impact of the conditions of the thermoplastics injection moulding process on the properties of injection moulded products. He is an author or coauthor of 98 published scientific publications and an author of several dozen lectures and papers, as well as implementation research reports on polymer processing, largely concerning extrusion process technology, machines and devices used in extrusion processes. He is the author and co-author of 22 patents, patent applications and utility models. He is a laureate of 3 scientific grant competitions and has also headed two scientific and research grants connected with polymer extrusion. These are research projects financed by Poland's Ministry of Science and Higher Education. His scientific achievements resulted in his participation, as a co-researcher, in 6 research projects financed by Poland's Ministry of Science and
Higher Education and in the project FP7-PEOPLE-2010-IRSES.

Assoc. prof. Ludmila Dulebová, Ing. PhD. is associate professor at the Technical University of Košice, Faculty of Mechanical Engineering, Department of Automobile Production. She graduated in 1983 at the VŠT Košice and obtained the PhD. degree (2008) in 23-07-9 Mechanical Engineering Technology and Materials at the Technical University of Košice. Her research areas are processing and simulation of injection molding, as well as testing and analysis of the properties of polymer materials. She is a co-author of one monography and two textbooks. She is an author or co-author of 95 published scientific publications and two her paper was registered in Current Contents paper, 21 papers were registered in Web of Science and SCOPUS. She is co-author of two patents. 